This is well shown in a case of Bolt, in which a man, aged 38, had the abdomen and the lower thorax crushed between two cars. He was wearing at the time a tightly fitting cap. The discolouration affected the whole of the face and neck except the part supported by the rim of the cap, thus showing the condition to be due to mechanical distension rather than any nerve paralysis. ${ }^{4}$

In the conjunctivæ, where the support afforded to the vessels is very slight, actual extravasations of blood occur, but these are not generally found in the other tissues of the discoloured area.

Pulmonary symptoms can only occur when the pressure on the heart itself is extreme, for the increase of tension in the right auricle finds a ready outlet through the superior vena cava rather than the stronger right ventricle, and the pulmonary veins and left atrium are so protected by their anatomical position as to escape any direct compression. If the ribs are fractured pulmonary symptoms arise from this local injury and not from the abdominal pressure per se.

Brain symptoms occur, but not so markedly as one would at first think. The vertebral veins are well supported and would not yield much to any added pressure. The same holds good, but to a less extent, with the deeply placed internal jugular, contained with its companion artery and nerve in a special fibrous sheath. The main outlet for the pressure must come on the external jugular with its superficial course and ill-supported walls.

We thus see that the only factors determining the area affected are: (a) The absence of venous valves sufficiently strong to prevent the reversal of blood flow. To do this they must hold up against the abdominal pressure in proportion to the respective areas, that of the abdomen being represented by inches and that of the veins by millimetres. And (b) the amount of support afforded by the surrounding tissues to the valveless veins. Hence the chief effect corresponds to the area served by the external jugular, the internal jugular and vertebral being less affected. An interesting point in the case now recorded is the extension of the discolouration on the third day to a line half an inch below the clavicles and the appearance of petechiæ in the axillæ. This may be explained anatomically. The superior intercostal veins empty into the innominate veins or rarely into the vertebral, both of which are distended and under pressure.

The last point in the pathology is the actual cause of the cyanosis. The circulation through normal tissues is so rapid that the exchange of $\mathrm{CO}_{2}$ for $\mathrm{O}_{2}$ does not make any marked difference in the colour of the blood. In the condition under consideration the dilatation of the veins to several times their normal extent without any correspond. ing arterial enlargement means that the bloodstream becomes sluggish and the tissues abstract from the hæmoglobin all the oxygen, causing the extreme discolouration which only disappears when the vein has returned to its normal calibre and the current of blood its normal rate of flow.

We are now in a position to see why these cases are so rare. Abdominal and thoracic crushes are common enough and often so severe as to cause death within a short time, but here we must have an even continuous pressure which by its influence will squeeze all the blood out of the abdomen. This occurs when a patient is held for some few minutes between two opposing surfaces which do

4 See also Randolph Winslow's case quoted above. not further approach each other-i.e., ias in the jaws of a vice. This is sufficient to compress the structures of the abdomen, but not enough to cause severe fracture or injury to the nerves and abdominal viscera.

I am indebted to my colleague, Dr. W. F. Chambers, under whom the patient was admitted, for the privilege of studying this case.

Folkestone.

\section{SOME OBSERVATIONS ON THE CONDITION OF THE LUNGS DURING RECOVERY FROM CHEST WOUNDS.}

By Professor T. G. BRODIE, M.D., F.R.S., Professor J. J. MACKENZIE, M.D., CAPTAINS, C.A.M.c., NO. 4 CANADIAN GENERAL HOSPITAL, UNIVERSITY

ASSISTED BY

Mrss W. C. CULLIS, D.Sc., AND

Mrs. E. M. TRIBE, B.Sc.,

LONDON (ROYAL FREE HOSPITAL) SCHOOL OF MEDICINE FOR WOMEN.

DURING the past four months we have been carrying out some observations upon the capacity of, and the circulation through, the lungs in soldiers recovering from chest wounds. In this connexion we have made measurements of the residual air and dead space, employing both Haldane's $\mathrm{CO}_{2}$ method and the hydrogen method, and also of the volume of the circulation through the lungs, using Krogh's nitrous oxide method for the purpose.

While our observations are not yet sufficiently advanced to enable us to make any detailed and definite statements, they indicate certain results which we think are of practical value. The patients studied were recovering from pneumothorax, hæmothorax, or empyema. When we began working upon them they all showed a very considerable limitation of movement upon the injured side.

In all cases we found the total blood flow through the lungs, as estimated by the nitrous oxide method, to be considerably above the normal. As our work proceeded we found reason to believe that the method gave results which were too high, and we have, therefore, adopted modifications which we hope will overcome the existing defects. In any case, however, the results obtained upon patients always showed higher, and often considerably higher, rates of flow than those obtained upon normal individuals of about the same weight. It must be remembered, too, that the estimate of the blood flow is a physiological one--that is, it only takes into account the blood flow through the lung surfaces at which active absorption of the nitrous oxide is taking place, and leaves out of account any of the flow through that part of the lung which is so damaged as to be incapable of absorbing. Consequently, our estimate is lower than the total blood flow. These facts indicate, therefore, that the compensatory increase of blood flow is proportionately greater than the diminution of respiratory surface owing to damage to the lung.

Our measurements of the residual air have given us very interesting results. As the patients gradually regained the use of the damaged parts of the lung, so we were able to follow quanti. tatively the increase in alveolar air and use it as a method of gauging the rate of recovery. In all cases this has been considerable and, in most, rapid. The dead space was found to vary considerably. 
There are many objections to all the methods which have been devised for measuring this quantity. We agree with Haldane and Henderson that the "physiological" dead space is always greater than the anatomical. In many of our patients it has appeared to be two to three times the normal. We are not yet in a position to offer an explanation of these results.

In offering suggestions for the lines upon which treatment should be directed, we can confidently recommend the regular employment of respiratory exercises. All those which we have so far employed have proved most beneficial. Of the many which have been suggested we have most frequently used that of simple deep and forceful inspirations. Up to the present this has been the one we have most thoroughly tested. It is so simple to carry out and has proved so effective that we have not found it necessary so far to employ any other. We, however, intend to test others and follow the results by our quantitative methods. The instructions we give to the patients are of the simplest - viz., on frequent occasions during the day to take some 10 or 12 of the deepest possible inspirations, instructing them to use a considerable amount of force in doing so.

For the purposes of our work, we have had suitable patients placed at our disposal at the Military Hospital, Endell-street, and we wish to express our great indebtedness to the authorities of the hospital for the assistance and facilities they have given us. Our laboratory work, by kind permission of the council of the school, has been conducted in the physiological laboratories of the London (Royal Free Hospital) School of Medicine for Women.

We wish also to thank the University of Toronto and several private subscribers in Toronto, who by providing the necessary apparatus have enabled us to undertake this investigation. Our indebtedness must also be expressed to the National Medical Research Committee, who have put at our disposal a research grant for the provision of skilled assistance in the processes of gas analysis, and a grant towards the expenses of the laboratory work.

\section{NYSTAGMUS AND ALLIED CONDITIONS.}

\section{BY JAUES ALEXANDER WILSON, M.D.GLASG.,} ASSISTANT SURGEON, OPHTHALMIC INSTITUTION, GLASGOW.

THE first part of this paper gives some details of 200 consecutive cases of nystagmus with some deductions therefrom.

Age.-The ages were as follows :-

5 years and under... 23 cases. 21 to 30 years ... 39 cases.

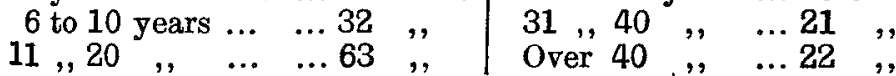

The ages of these patients indicate that nystagmus is more prevalent in youth and that it tends to disappear in adult life.

Sex.-Males, 105 ; females, 95.

Vision of 400 eyes-that is, taking the eyes singly :-

$$
\begin{aligned}
& \begin{array}{lllll|lllll}
6 / 6 & \ldots & \ldots & \ldots & 9 & 6 / 24 & \ldots & \ldots & \ldots & 32
\end{array} \\
& \begin{array}{rrrrr|rrrrr}
6 / 9 & \ldots & \ldots & \ldots & 9 & 6 / 24 & \ldots & \ldots & \ldots & 32 \\
6 / 10 & \ldots & \ldots & \ldots & 10 & 6 / 36 & \ldots & \ldots & \ldots & 54
\end{array}
\end{aligned}
$$

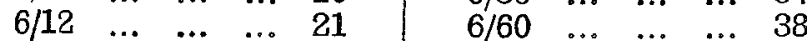

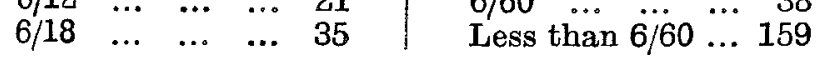

$$
\begin{aligned}
& \begin{array}{llllll}
\text { Young children } & \ldots & \ldots & \ldots & \ldots & 42
\end{array}
\end{aligned}
$$

Excluding the young children, then, 88 per cent. of
Only 6 cases had good or fair vision in both eyes, and these are-hereditary nystagmus, 1 case; and miners, 5 cases.

Refraction of 400 eyes:-

$\begin{array}{llllllrl}\text { Myopia and myopic astigmatism } & \ldots & 39 & \text { per cent. } \\ \text { Mixed astigmatism } & \ldots & \ldots & \ldots & \ldots & 6 & , \\ \text { Hypermetropia } & \text { and } & \text { hypermetropic } & 6 & \\ \quad \text { astigmatism } & \ldots & \ldots & \ldots & \ldots & \ldots & 30 & , \\ \text { Emmetropia } . . . & \ldots & \ldots & \ldots & \ldots & \ldots & 7 & , \\ \text { Unknown or estimation impossible } & \ldots & 12 & , \\ \text { Eyes shrunken or wanting... } & \ldots & \ldots & 6 & ,\end{array}$

Emmetropic or normal refraction is found in the following cases: Miners, 5 ; hereditary nystagmus, 1 ; corneal opacities, 3; optic atrophy, 6 . In all the other cases there are errors of refraction and defective vision.

There are 24 miners in the series, and the refrac; tive conditions in these cases are: Myopic, 10; hypermetropic, 5 ; emmetropic, 5 ; unknown, 4.

There are 8 albinos, and the refractive conditions in these cases are: Myopic, 2 ; hypermetropic, 6.

The following conditions were present:-

Corneal opacities 44 cases. |Choroiditis... $\quad . .8 \quad 8$ cases. Ordinary cataract 11 ," Convergent squint 34 , Anterior capsular $5, \quad$ Divergent squint 12 , cataract ......$\} 5, "$ Lenses dislocated 2, Optic atrophy ... 11 ,, Buphthalmia ... 2 ,"

These conditions produce imperfect retinal images, or-as in the cases of optic atrophy-prevent the transmission of retinal impressions to the brain.

Time of onset.-This is shown below:-

At birth or within 3 months ... ... 18.5 per cent.

Over 3 months and under 5 years $\ldots .449 .5$,

$\begin{array}{llllllll}5 \text { to } 10 \text { years } & \ldots & \ldots & \ldots & \ldots & \ldots & 15.0 & \text {, }\end{array}$

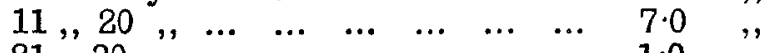

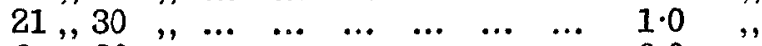

$\begin{array}{llllllllll}\text { Over } 30 & , & \ldots & \ldots & \ldots & \ldots & \ldots & \ldots & 6 \cdot 0 & , \text {, }\end{array}$

$\begin{array}{lllllllll}\text { Unknown } & \ldots & \ldots & \ldots & \ldots & \ldots & \ldots & 3 \cdot 0 & \text {, }\end{array}$

The following case merits recording, on account of the late time of onset.

Mrs aged 53, has $12 \mathrm{D}$. of myopia and has always had defective vision. She has five children and of these two have myopia. Her parents had good vision, but her father had two sisters who were also myopic. As far as she knows there is no nystagmus in her family. This woman has nystagmus, which she says only came on eight months ago. The oscillations are of medium rapidity, lateral and concomitant. The eyeballs become steady when she looks downwards or to the sides, but not when she looks upwards. Objects she looks at seem to shake. There is no evidence of disseminated sclerosis or cerebellar disease.

Movements.-Lateral, 61 per cent.; rotatory, 16 per cent.; oblique or irregular, 13 per cent.; vertical, 6 per cent.; lateral and rotatory, 4 per cent.

Concomitancy of the morements. - The investigation of this point is rendered much easier by the use of approximating prisms-prisms with their edges together-through which the eyeballs can be seen edge to edge or overlapped. I have elsewhere described these prisms and given instructions for their use. ${ }^{1}$ In some cases the concomitancy could not be determined, as the movements were too rapid or were irregular; otherwise, with three doubtful cases, the movements were all concomitant-that is, both eyes rotated to the right together and to the left together, instead of diverging together and converging together or one eye turning up while the other turned down.

One of these doubtful cases I thought was nonconcomitant-converging at the same time; but after carefully observing the case on several occasions I decided that one eye simply made a larger swing than the other and that the movements were really concomitant. The second case 